\section{OPEN ACCESS}

Edited by:

Olivier Kah

Centre National de la Recherche Scientifique UMR 6026, France

Reviewed by:

Rafael Vazquez-Martinez,

University of Cordoba, Spain

Andreas Stengel,

Charité Universitätsmedizin Berlin,

Germany

*Correspondence:

Li F. Chan,

Centre for Endocrinology, William Harvey Research Institute, Barts and the London School of Medicine and Dentistry, Queen Mary University of London, Charterhouse Square, London EC1M 6BQ, UK l.chan@qmul.ac.uk

Specialty section:

This article was submitted to Neuroendocrine Science, a section of the journal Frontiers in Neuroscience

Received: 12 December 2014 Accepted: 28 May 2015 Published: 10 June 2015

Citation:

Jackson DS, Ramachandrappa $S$, Clark AJ and Chan LF (2015) Melanocortin receptor accessory proteins in adrenal disease and obesity. Front. Neurosci. 9:213. doi: 10.3389/fnins.2015.00213

\title{
Melanocortin receptor accessory proteins in adrenal disease and obesity
}

\section{David S. Jackson, Shwetha Ramachandrappa, Adrian J. Clark and Li F. Chan*}

Centre for Endocrinology, William Harvey Research Institute, Barts and the London School of Medicine and Dentistry, Queen Mary University of London, London, UK

Melanocortin receptor accessory proteins (MRAPs) are regulators of the melanocortin receptor family. MRAP is an essential accessory factor for the functional expression of the MC2R/ACTH receptor. The importance of MRAP in adrenal gland physiology is demonstrated by the clinical condition familial glucocorticoid deficiency type 2 . The role of its paralog melanocortin-2-receptor accessory protein 2 (MRAP2), which is predominantly expressed in the hypothalamus including the paraventricular nucleus, has recently been linked to mammalian obesity. Whole body deletion and targeted brain specific deletion of the Mrap2 gene result in severe obesity in mice. Interestingly, Mrap2 complete knockout $(\mathrm{KO})$ mice have increased body weight without detectable changes to food intake or energy expenditure. Rare heterozygous variants of MRAP2 have been found in humans with severe, early-onset obesity. In vitro data have shown that Mrap2 interaction with the melanocortin-4-receptor (Mc4r) affects receptor signaling. However, the mechanism by which Mrap2 regulates body weight in vivo is not fully understood and differences between the phenotypes of Mrap2 and Mc4r KO mice may point toward Mc4r independent mechanisms.

Keywords: melanocortin receptors, accessory proteins, adrenal function, obesity, knockout mouse model

\section{The Melanocortin Receptor Family}

Melanocortin receptors (MCRs) comprise a family of five, class A, G protein-coupled receptors designated MC1R-MC5R with diverse physiological roles. MCRs are found in chordates and are regarded as having evolved from a single ancestral receptor, possibly corresponding most closely to MC4R (Dores, 2013). Signaling by MCRs has primarily been observed as occurring through the stimulatory $\alpha$ unit Gs which activates adenylyl cyclase to produce cAMP, although other pathways have been implicated (Yang, 2011). Receptor properties such as biased agonism (MC4R) and constitutive activity (MC3R and MC4R) have also been reported (Nijenhuis et al., 2001; Breit et al., 2011).

The melanocortin agonist ligands for MCRs, adrenocorticotropic hormone (ACTH) and the melanocyte stimulating hormones $\alpha \mathrm{MSH}, \beta \mathrm{MSH}$, and $\gamma \mathrm{MSH}$, are neuropeptides derived by enzymatic cleavage from proopiomelanocortin (Pritchard et al., 2002). Their relative potencies are set out together with the natural antagonists in Table 1. The natural peptide antagonists comprise agouti and agouti related protein (AgRP) (Cone, 2006). Agouti was first discovered as a high affinity MC1R antagonist, following studies on genetic determinants of yellow coat color and obese phenotype observed in agouti mouse strains (Lu et al., 1994). Agouti-related 
TABLE 1 | Natural ligands of the melanocortin receptor family (Kiefer et al., 1997; MacNeil et al., 2002; Cone, 2006).

\begin{tabular}{|c|c|c|c|c|}
\hline Receptor & Relative potency of agonists & Antagonists & Main site of expression & Primary Function \\
\hline MC1R & $\alpha \mathrm{MSH}=\beta \mathrm{MSH}=\mathrm{ACTH}>\gamma \mathrm{MSH}$ & Agouti & Melanocytes & Pigmentation, inflammation \\
\hline MC2R & ACTH only & & Adrenal cortex & Adrenal steroidogenesis \\
\hline MC3R & $\alpha \mathrm{MSH}=\beta \mathrm{MSH}=\mathrm{ACTH} \approx \gamma \mathrm{MSH}$ & Agouti; AgRP & CNS, Gl tract, Kidney & Energy homoestasis, inflammation, Entrainment to meal intake \\
\hline MC4R & $\alpha \mathrm{MSH}=\beta \mathrm{MSH}=\mathrm{ACTH}>>\gamma \mathrm{MSH}$ & Agouti; AgRP & CNS & Energy homeostasis, thermogenesis, appetite regulation, erectile function \\
\hline MC5R & $\alpha \mathrm{MSH}>\beta \mathrm{MSH}=\mathrm{ACTH}>>\gamma \mathrm{MSH}$ & & Exocrine cells & Exocrine function, regulation of sebaceous glands \\
\hline
\end{tabular}

protein (AgRP) was later identified as a MC3R and MC4R antagonistic peptide almost identical in size and genomic structure to Agouti (Ollmann et al., 1997; Shutter et al., 1997). Since then it has been shown that both Agouti and AgRP can act as inverse agonists in cAMP assays inhibiting MC1R and MC4R constitutive activity respectively (Vage et al., 1997; Chai et al., 2003). However, such inverse agonists to the MC4R can act as agonists through intracellular ERK1/2 signaling (Breit et al., 2011; Mo and Tao, 2013). A number of additional molecules have been shown to alter MCR function in a variety of ways including $\beta$ defensin 3 (Beaumont et al., 2012; Swope et al., 2012), attractin (also known as mahogany), and mahogunin (He et al., 2001).

\section{MC1R}

Pigmentation and the control of the inflammatory functions of the immune system are dependent on MC1R. Stimulation of MC1R in skin and hair follicle cells by $\alpha \mathrm{MSH}$ results in melanogenesis producing dark skin or hair in many species, including humans (Beaumont et al., 2011). Variants in MC1R in humans are associated with red hair, pale skin, and increased risk to skin cancer. This action of $\alpha \mathrm{MSH}$ is antagonized in vivo by agouti (Lu et al., 1994). MC1R is present on human leukocytes, and on murine macrophages, and has been implicated in the antiinflammatory properties of $\alpha \mathrm{MSH}$ (Star et al., 1995; Catania et al., 2004).

\section{MC2R}

MC2R is unique as it is the only MCR that binds to a specific ligand ACTH. The receptor is predominantly expressed in the adrenal gland. In humans, the inability of ACTH to activate MC2R leads to failure of the adrenal gland to generate cortisol, resulting in the potentially lethal condition of familial glucocorticoid deficiency (FGD) (Clark et al., 1993). Mutation in MC2R leads to FGD type 1. The FGD phenotype was reproduced in the MC2R knockout mouse, although the mice also had evidence of mineralocorticoid deficiency (Chida et al., 2007). $\mathrm{MC} 2 \mathrm{R}$ is also found in human and mouse bone where it is thought to be involved in osteoblast proliferation (Zhong et al., 2005). Interestingly, patients with FGD type 1 have tall stature (Elias et al., 2000). MC2R has also been detected in human subcutaneous fat (Smith et al., 2003) and the developing testis (O'Shaughnessy et al., 2007). In mouse adipose tissue, MC2R may be implicated in the release of non-esterified fatty acids from adipocytes (Moller et al., 2011).

\section{MC3R}

MC3R is primarily expressed in the central nervous system in the arcuate nucleus of the hypothalamus and limbic areas, where it affects food utilization/partitioning and food anticipatory behavior (Sutton et al., 2008, 2010; Begriche et al., 2011). Although loss-of-function mutations in MC3R have been identified in humans with obesity, there is still uncertainty if these variants are truly causative (Lee et al., 2007; Mencarelli et al., 2011). In mice, MC3R is essential for the maintenance of a circadian rhythm of activity related to feeding behavior (Begriche et al., 2012). Both central and peripheral MC3R are involved in energy utilization (Begriche et al., 2011). MC3R has also been implicated in the anti-inflammatory processes in murine macrophages (Getting et al., 2006; Leoni et al., 2008; Montero-Melendez et al., 2014).

\section{MC4R}

MC4R is thought to bind principally to $\alpha \mathrm{MSH}$ in the paraventricular nucleus (PVN) of the hypothalamus (CNS), a region crucial in the control of food intake. Global homozygous deletion of MC4R in mice results in hyperphagia, increased fat and lean mass, increased body length, reduced activity, and reduced metabolic rate (Huszar et al., 1997; Balthasar et al., 2005). Inactivating mutations in MC4R are the single most common form of monogenic obesity in humans (Farooqi et al., 2003). Common variants near the MC4R locus are associated with adiposity, body weight, risk of obesity and insulin resistance at a population level (Chambers et al., 2008; Loos et al., 2008). The function of MC4R has also expanded over recent years and involvement in autonomic regulation of thermogenesis and glycaemia (Berglund et al., 2014), regulation of sympathetic and parasympathetic control of blood pressure (Sohn et al., 2013) and anhedonia (Lim et al., 2012) have all been described. A role in erectile function and sexual behavior have also been reported (van der Ploeg et al., 2002). Most recently, MC4R expression has been demonstrated in enteroendocrine L cells and regulates the release of peptide YY (PYY) and glucagon-like peptide 1 (GLP-1) (Panaro et al., 2014).

\section{MC5R}

The need for MC5R activity in the secretory function of exocrine glands is well-known (Chen et al., 1997; van der Kraan et al., 1998). MC5R is widely expressed and mice deficient of Mc5r have impaired water repulsion and thermoregulation (Chen et al., 1997). There are some suggestions that MC5R expression in the zona glomerulosa of the adrenal gland may be involved in 
melanocortin stimulated aldosterone secretion (Vinson et al., 1980; Griffon et al., 1994; van der Kraan et al., 1998), although this is not in keeping with the lack of an adrenal phenotype in Mc5r knockout mice (Chen et al., 1997). Stimulation of MC5R in 3T3$\mathrm{L} 1$ adipocytes with $\alpha \mathrm{MSH}$ has been shown to result in lipolysis, through cAMP production, and impairment of re-esterification of fatty acids, through the ERK1/2 pathway (Rodrigues et al., 2013).

\section{The Melanocortin Receptor Accessory Proteins, MRAP, and MRAP2}

\section{Discovery of MRAP and MRAP2}

The discovery of MRAP (sometimes referred to as MRAP1) in 2005 by Metherell et al. has provided insight into a novel aspect of MCR regulation, previously unknown (Metherell et al., 2005). By studying the clinical condition FGD it was noted that only approximately $25 \%$ of FGD cases were attributable to mutations of MC2R (Chan et al., 2009). Failure of MC2R to traffick to the cell surface in cells other than those derived from an adrenal lineage suggested the presence of an adrenal specific accessory protein (Noon et al., 2002). Using whole genome SNP array genotyping on informative families, mutations in the gene encoding a protein derived from open reading frame 61 of human chromosome 21 (C21orf61), corresponding to a murine adipocyte transmembrane protein (Xu et al., 2002), was identified to cause FGD type 2 (Metherell et al., 2005). This gene was subsequently named melanocortin-2-receptor accessory protein (MRAP). The human MRAP gene contains six exons, exons 5 and 6 are alternatively spliced to give rise to two MRAP isoforms, MRAP $\alpha$ (exon1-5), and MRAP $\beta$ (exon 1-4 and 6). Exons 1 and 2 are not translated in the human isoforms whilst rodents do not have the corresponding exons 1 and 2 and produce only one form of the protein (Webb and Clark, 2010). The translated small single pass transmembrane domain protein differs from other known GPCR accessory proteins (Webb and Clark, 2010) and has been shown to adopt a unique anti-parrallel homodimer conformation at the cell surface (Sebag and Hinkle, 2007; Cooray et al., 2008). Both isoforms are present with MC2R in human adrenal tissue (Metherell et al., 2005). The presence of either MRAP $\alpha$ or MRAP $\beta$ is essential for MC2R cell surface expression and signaling (Metherell et al., 2005; Roy et al., 2007; Cooray et al., 2008; Hinkle and Sebag, 2009), but the response of MC2R to ACTH may differ between the two isoforms, with MRAP $\alpha$ increasing potency but MRAP $\beta$ increasing maximal response (Roy et al., 2007).

Human C6orf117 was identified as a possible paralog to MRAP (Metherell et al., 2005). This gene was subsequently designated MRAP2. The human MRAP2 gene has four exons, exons 2-4 code for a 205 amino acid residue protein (Chan et al., 2009). MRAP2 is thought to adopt a similar dual topology at the cell surface (Chan et al., 2009). Mouse Mrap2 gene differs in having two small untranslated exons 1 and 1a (Asai et al., 2013). Zebra fish has a single Mrap and two forms of Mrap2, designated mrap2a and mrap2b (Agulleiro et al., 2010). Mrap2a and mrap2b appear to have different actions and appear at differing time points in zebrafish development (Sebag et al., 2013). Study of the conservation between the Mraps of lampreys, cartilaginous fish, teleosts, and tetrapods has indicated that MRAP2 is the ancestral gene (Webb and Clark, 2010; Dores, 2013).

\section{Tissue Expression of MRAPs}

Both MRAP $\alpha$ mRNA and MRAP $\beta$ mRNA are found in human adrenal tissue, testis, breast tissue, ovary, fat, skin, and jejunum, MRAP $\alpha$ mRNA alone being more widely distributed in digestive tract tissues, the immune system, and in thyroid and pituitary, and MRAP $\beta$ mRNA alone appearing in brain (Metherell et al., 2005). Evidence for human MRAP mRNA has been detected in the hippocampus, prefrontal cortex, cerebellum, and spinal cord, among other tissues (Gardiner et al., 2002). MRAP expression clearly extends beyond MC2R expression, where expression of $\mathrm{MC} 2 \mathrm{R}$ has been reported in the adrenal, bone, adipose tissue, ovaries, testes, skin, and the pituitary (Metherell et al., 2005). MRAP2 mRNA was detected in human adrenal and brain tissue (Chan et al., 2009). In mice Mrap2 mRNA was detected by RT-PCR in a wider number of tissues including hypothalamus, pons, brainstem, cerebellum, eye, thymus, pituitary, adrenal, gonads, skin, and fat (Asai et al., 2013). A recent report demonstrated that MRAP2 expression in human endometrium was significantly down regulated during endometrial transition from its pre-receptive state to the receptive state ( $\mathrm{Hu}$ et al., 2014), although the physiological significance of this change is unknown.

\section{MRAPs and Melanocortin Receptors In vitro}

Several groups have studied the effects of MRAPs on MCR cell surface expression and function in a number of heterologous systems. The absolute requirement of MRAP for the MC2R trafficking and function is clear and recapitulated by many groups (Metherell et al., 2005; Roy et al., 2007; Sebag and Hinkle, 2007). Transient transfection of MRAP $\alpha$ and MRAP2 with MCRs into $\mathrm{CHO}$ cells confirmed that MRAP is necessary for surface expression of MC2R and showed that MRAP2 also can enable surface expression of MC2R (Chan et al., 2009). One study using HEK293 cells reported MC2R surface expression in the absence of MRAP (Roy et al., 2007), although this may well have been due to endogenous MRAP2 in some HEK293 cell-lines (Roy et al., 2010). In addition to surface expression, there are suggestions that MRAPs could influence the post-translational glycosylation of MC2R and MC4R (Kay et al., 2013a). MRAP is essential for MC2R to respond to $\mathrm{ACTH}$ and although the presence of MRAP2 can enable MC2R to respond to ACTH this is unlikely to be of physiological significance (Gorrigan et al., 2011). The interplay between MRAP and MRAP2 on MC2R function is less clear. Some suggest that MRAP and MRAP2 act in an antagonistic manner whilst others show no effect or an additive effect on MC2R function in the presence of both MRAPs (Chan et al., 2009; Agulleiro et al., 2010; Sebag and Hinkle, 2010).

The reported results on other MCRs vary, which in part may be due to differences in ligands, cell-lines, ratio of MRAP to MCR expressed or be dependent on the ortholog studied. MRAPs have no effect on the trafficking of MC1R and MC3R but reduce 
surface expression of MC4R and MC5R (Chan et al., 2009; Sebag and Hinkle, 2009, 2010). In the case of MC5R, MRAP appeared to disrupt MC5R dimerization (Sebag and Hinkle, 2009). Reduced cAMP generation in response to NDP-MSH was demonstrated for human MC1-5R (Chan et al., 2009). Other groups have also shown a significant reduction in MC5R signaling in the presence of MRAPs (Sebag and Hinkle, 2010; Kay et al., 2013b). These studies however found no change in MC4R potency (Sebag and Hinkle, 2010) or an increase in MC4R function (Asai et al., 2013; Sebag et al., 2013). MC4R constitutive activity does appear to be affected in the presence of MRAP/MRAP2 (Asai et al., 2013; Kay et al., 2013b; Sebag et al., 2013). The two isoforms of Mrap2 in zebrafish appears to have differing effects on Mc4r function. Mrap2a inhibits activation of Mc4r whilst Mrap2b suppressed the constitutive activity of the receptor but greatly increased the potency of $\alpha$ MSH (Sebag et al., 2013).

\section{MRAPs and Adrenal Disease}

\section{MRAP}

Loss-of-function mutations in MRAP give rise to FGD type 2 (Metherell et al., 2005). Patients with FGD type 2 present with symptoms and signs resulting from isolated glucocorticoid deficiency and excess plasma ACTH (Chung et al., 2010). FGD type 2 patients present significantly earlier than those with FGD type 1 individuals harboring MC2R mutations, with the exception of those patients with missense MRAP mutations who present later and with a milder phenotype (Hughes et al., 2010).

In keeping with the importance of MRAP's role in glucocorticoid production, with both MRAP and MC2R are highly expressed in the zona fasciculata. However, the highest levels of expression are found in the undifferentiated zone, believed to contain adrenal stem cells, suggesting that MC2R and MRAP maybe important in adrenal development and/or maintenance (Gorrigan et al., 2011). The adrenal histology from deceased FGD patients would support this notion revealing glomerulosa cell disorganization and loss of fasciculata and reticularis cells (Clark and Weber, 1998).

MRAP is a critical component of the hypothalamic-pituitaryadrenal axis, involved in adrenal responsiveness to ACTH and possibly other adrenal disease processes. In rats, the transcription of Mrap RNA closely tracks the normal ultradian pulses of ACTH and, together with similar patterns of transcription and related protein processing of other components of adrenal steroidogenesis, suggests that Mrap protein availability is closely tied to need for signaling in response to ACTH (Liu et al., 2003).

One study assessed MC2R, MRAP, and MRAP2 expression in human adrenal tissue derived from normal and hyperplastic adrenal gland, and from adrenocortical adenomas and carcinomas (Hofland et al., 2012). Their data suggested that the effect of ACTH stimulation on the expression of the ACTH receptor complex comprising MC2R, MRAP and MRAP2 assists in the production of a functioning complex, although the level of MRAP2 being insufficient to reduce its sensitivity to ACTH.

\section{MRAP2}

In vitro, MRAP2 has been shown to enable MC2R trafficking to the cell surface and subsequent signaling. N-linked glycosylation appears critical in this process (Chan et al., 2009). The dose of ACTH required to activate the receptor is however 1000 times higher than that compared to MRAP (Sebag and Hinkle, 2010; Gorrigan et al., 2011), which would explain the inability of MRAP2 to rescue MC2R function in patients with MRAP mutations. Furthermore, significantly lower levels of Mrap2 expression compared with Mrap expression are found in adult rat adrenal gland. Unlike Mrap, which is highly expressed in the zona fasciculata, Mrap2 appears sparsely expressed throughout the adult adrenal cortex (Gorrigan et al., 2011). Although, Mrap2 appears highly expressed in the developing adrenal gland, to date no adrenal phenotype have been described in the Mrap2 KO mice (Gorrigan et al., 2011; Asai et al., 2013).

\section{MRAPs and Obesity}

\section{MRAP2}

MRAP2 was shown to interact with all MCRs and the expression in the hypothalamus and PVN pointed to a role in central melanocortin regulation of metabolism and appetite (Chan et al., 2009). A recent publication describing obesity in rodents and humans with MRAP2 deficiency has demonstrated that this is indeed the case (Asai et al., 2013). Furthermore, zebrafish deficient of MRAP2 isoforms was shown to have disrupted growth and development supporting the role of MRAP2 in metabolism homeostasis (Sebag et al., 2013).

Phenotypically, global Mrap2 KO mice on an sv129 genetic background fed a chow ad libitum diet develop severe obesity at a young age and were found to be significantly heavier than their wild type counterparts at approximately 6 weeks of age. Mrap $2^{-/-}$mice have increased body length and fat deposits, whilst percentage lean mass was reduced. Heterozygous Mrap $^{+/-}$mice have an intermediate phenotype (Asai et al., 2013).

Serum leptin was elevated in Mrap2 null mice, which normalized following weight loss through food restriction. No differences in fasting serum insulin concentration, response to glucose load or serum T3 and T4 levels were detectable between null and wild-type animals, whilst Mrap2 $2^{-/-}$males have lower $24 \mathrm{~h}$ urine epinephrine and norepinephrine. AgRP mRNA levels in the hypothalamus are increased in Mrap2 null animals without changes in POMC mRNA. Although brown fat deposit was enlarged in obese mice, response to cold challenge normal and Ucp1 mRNA levels in brown fat increased appropriately when mice were subjected to $4^{\circ} \mathrm{C}$ for $18 \mathrm{~h}$ (Asai et al., 2013).

Interestingly, no increase in food intake was detected and despite paired feeding, Mrap2 $2^{-/-}$mice became significantly heavier in weight compared with $\mathrm{Mrap}^{+/+}$littermates. Food restriction in Mrap2 $2^{-/-}$mice (90\% (females) or $87 \%$ (males) of wild type intake) was required to normalize their weight gain to that of wild-type Mrap2 $2^{+/+}$mice. Faecal energy content was also indistinguishable between Mrap2 $2^{-/-}$and Mrap2 $2^{+/+}$mice (Asai et al., 2013). 
Analysis of young mice prior the divergence of weight between null and wild-type mice demonstrated indistinguishable $24 \mathrm{~h}$ energy expenditure and respiratory exchange ratio (RER) when measured by indirect calorimetry. There was no difference in locomotor activity during the day or night and body temperature even when challenged by cold was not different (Asai et al., 2013).

Asai et al. demonstrated that Mrap2 was expressed in several sites of the mouse brain and in the PVN co-localized with Mc4r expressing neurons (Asai et al., 2013), suggestive of an MC4R dependent mechanisms. Mrap2 ${ }^{-/-}$mice share some phenotypic similarities with Mc4r KO mice, which are heavier with increased length and adiposity. Heterozygous $\mathrm{Mc} \mathrm{r}^{+/-}$ mice have an intermediate weight phenotype (Huszar et al., 1997). In support of an MC4R mechanism, mice with conditional deletion of Mrap2 in Sim1 neurons that express Mc4r were equally obese and phenotypically similar to global Mrap2-/mice (Asai et al., 2013). However, differences exist between $\mathrm{Mrap}^{-/-}$and $\mathrm{Mc} 4 \mathrm{r}^{-/-}$mice. In $\mathrm{Mc} 4 \mathrm{r}^{-/-}$mice, obesity is attributable to hyperphagia and reduced energy expenditure. The Mc4r null mice also have increased lean mass (Balthasar et al., 2005; Sutton et al., 2006).

In humans, disabling mutations of MC4R are the most common cause of monogenic obesity and found in up to $6 \%$ of severely obese patients (Vaisse et al., 1998; Yeo et al., 1998). In comparison, genetic screening of two large obese pediatric cohorts identified only four rare heterozygous MRAP2 variants (N88Y, L115V, R125C, E24X) in patients with severe early onset obesity (Asai et al., 2013). The individual carrying the most damaging variant, E24X variant, was the most severely affected with a reported BMI of $63 \mathrm{~kg} / \mathrm{m} 2$ (BMI SDS 4.7) at the age of 19 years.

Data from zebrafish supports the notion that MRAP2 is an MC4R accessory protein capable of regulating the function of MC4R (Asai et al., 2013; Sebag et al., 2013). However, several lines of evidence from the Mrap2 $2^{-/-}$mice data would suggest the possibility of Mc4r independent mechanisms. Firstly, Mrap2 $2^{-/-}$ mice remain responsive to treatment with MTII, a Mc3r and Mc4r agonist, whilst anorexic response to MTII is abolished in $\mathrm{Mc} 4 \mathrm{r}^{-/-}$mice. Secondly, Mrap2 $2^{-/-}$and $\mathrm{Mc}_{4} \mathrm{r}^{-/-}$double

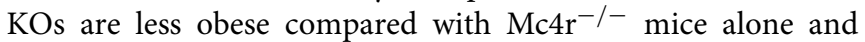
finally the Mrap $2^{-/-}$does not completely replicate $M c 4 r^{-/-}$ mice phenotype.

The phenotype of the Mc3r homozygous knockout mice is of interest. $\mathrm{Mc} \mathrm{r}^{-/-}$animals are not obviously hyperphagic but eventually become heavier than wild type mice on a standard chow diet, and have more adipose tissue and smaller bones, but no significant difference in energy expenditure (Chen et al., 2000; Begriche et al., 2011). Heterozygous Mc3r knockout mice are similar to wild type mice (Chen et al., 2000). More recently it has been shown that MRAP2, but not MRAP, localizes at the apical plasma membrane in the presence of MC3R in a polarized cell, MC3R also localizing at the apical membrane (Park et al., 2014). Receptors and other structures in neurons have precisely determined locations and are associated with dedicated trafficking mechanisms in which MRAPs may have a role.

There is no suggestion that Mrap2 plays a role in MC1R or MC2R function as Mrap2 $2^{-/-}$mice have normal coat color and corticosterone production (at baseline and when stressed) (Asai et al., 2013).

\section{MRAP}

It is not yet known if MRAP is associated with mammalian obesity. There is a single case report describing a family with a splice site mutation of MRAP. Family members homozygous and heterozygous for the mutation were obese compared with normal weighted unaffected members (Rumie et al., 2007). As yet the knockout mouse has not been reported. In murine 3T3-L1 cells,

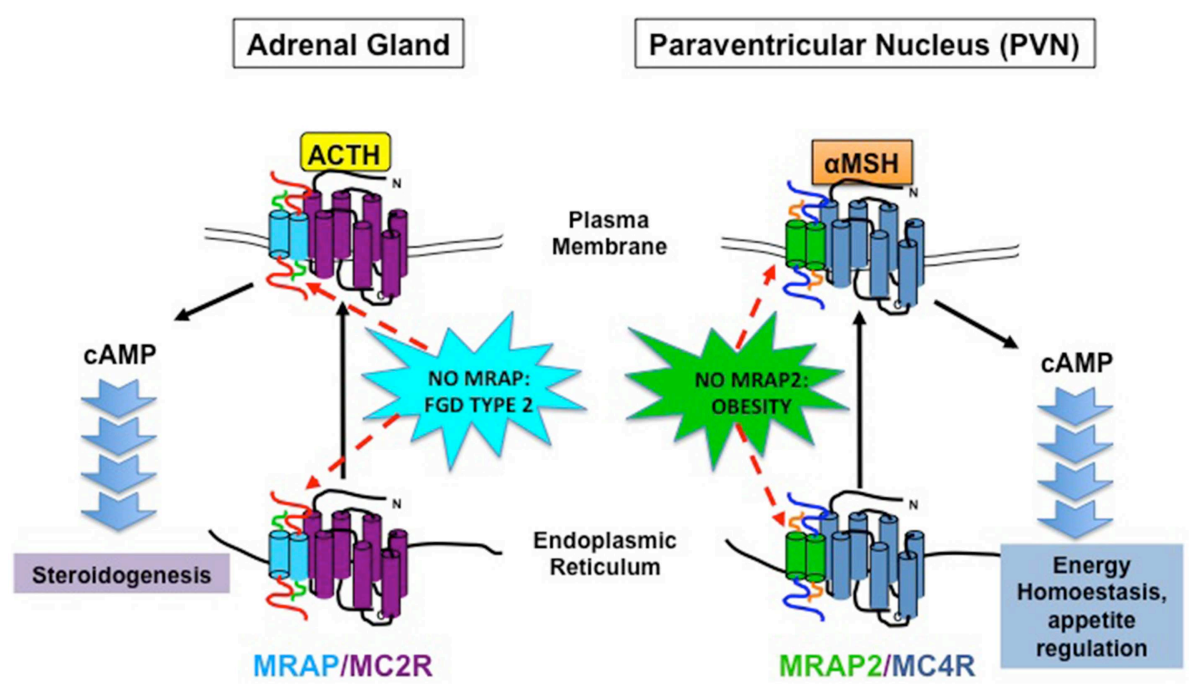

FIGURE 1 | Schematic Diagram illustrating MRAP and MRAP2 action on MC2R and MC4R, respectively and physiological consequence of MRAP and MRAP2 deficiency on adrenal steroidogenesis and energy homeostasis. 
ACTH triggers lipolysis and knockdown of Mrap in these cells substantially inhibits lipolysis (Kim et al., 2013). Furthermore, the promoter of Mrap was found to include a region binding the transcription factor PPAR $\gamma$ that regulates adipogenesis in fibroblasts (Tontonoz et al., 1994; Kim et al., 2013).

\section{Future of MRAPs}

The discovery of MRAP and MRAP2 has initiated a paradigm shift in our understanding of MCR and GPCR signaling (Figure 1). For MRAP, the ability to functionally express MC2R in non-adrenal cell lines has opened up many opportunities including screening for MC2R peptide antagonists (Bouw et al., 2014). Moreover, the finding that MRAP2 is associated with mammalian obesity is exciting and could provide a novel therapeutic target at a time when obesity is at epidemic levels. There are many scientific questions yet to be answered. For example, the precise mechanism of how MRAP2 causes obesity

\section{References}

Agulleiro, M. J., Roy, S., Sanchez, E., Puchol, S., Gallo-Payet, N., and CerdaReverter, J. M. (2010). Role of melanocortin receptor accessory proteins in the function of zebrafish melanocortin receptor type 2. Mol. Cell Endocrinol. 320, 145-152. doi: 10.1016/j.mce.2010.01.032

Asai, M., Ramachandrappa, S., Joachim, M., Shen, Y., Zhang, R., Nuthalapati, N., et al. (2013). Loss of function of the melanocortin 2 receptor accessory protein 2 is associated with mammalian obesity. Science 341, 275-278. doi: $10.1126 /$ science. 1233000

Balthasar, N., Dalgaard, L. T., Lee, C. E., Yu, J., Funahashi, H., Williams, T., et al. (2005). Divergence of melanocortin pathways in the control of food intake and energy expenditure. Cell 123, 493-505. doi: 10.1016/j.cell.2005.08.035

Beaumont, K. A., Smit, D. J., Liu, Y. Y., Chai, E., Patel, M. P., Millhauser, G. L., et al. (2012). Melanocortin-1 receptor-mediated signalling pathways activated by NDP-MSH and HBD3 ligands. Pigment Cell Melanoma Res. 25, 370-374. doi: 10.1111/j.1755-148X.2012.00990.X

Beaumont, K. A., Wong, S. S., Ainger, S. A., Liu, Y. Y., Patel, M. P., Millhauser, G. L., et al. (2011). Melanocortin MC(1) receptor in human genetics and model systems. Eur. J. Pharmacol. 660, 103-110. doi: 10.1016/j.ejphar.2010.11.040

Begriche, K., Levasseur, P. R., Zhang, J., Rossi, J., Skorupa, D., Solt, L. A., et al. (2011). Genetic dissection of the functions of the melanocortin-3 receptor, a seven-transmembrane G-protein-coupled receptor, suggests roles for central and peripheral receptors in energy homeostasis. J. Biol. Chem. 286, 40771-40781. doi: 10.1074/jbc.M111.278374

Begriche, K., Marston, O. J., Rossi, J., Burke, L. K., McDonald, P., Heisler, L. K., et al. (2012). Melanocortin-3 receptors are involved in adaptation to restricted feeding. Genes Brain Behav. 11, 291-302. doi: 10.1111/j.1601183X.2012.00766.x

Berglund, E. D., Liu, T., Kong, X., Sohn, J. W., Vong, L., Deng, Z., et al. (2014). Melanocortin 4 receptors in autonomic neurons regulate thermogenesis and glycemia. Nat. Neurosci. 17, 911-913. doi: 10.1038/nn.3737

Bouw, E., Huisman, M., Neggers, S. J., Themmen, A. P., van der Lely, A. J., and Delhanty, P. J. (2014). Development of potent selective competitive-antagonists of the melanocortin type 2 receptor. Mol. Cell Endocrinol. 394, 99-104. doi: 10.1016/j.mce.2014.07.003

Breit, A., Buch, T. R., Boekhoff, I., Solinski, H. J., Damm, E., and Gudermann, T. (2011). Alternative G protein coupling and biased agonism: new insights into melanocortin-4 receptor signalling. Mol. Cell Endocrinol. 331, 232-240. doi: 10.1016/j.mce.2010.07.007

Catania, A., Gatti, S., Colombo, G., and Lipton, J. M. (2004). Targeting melanocortin receptors as a novel strategy to control inflammation. Pharmacol. Rev. 56, 1-29. doi: 10.1124/pr.56.1.1 is not fully understood. It is intriguing that no difference in food intake or energy expenditure was detected in Mrap2 ${ }^{-/-}$ compared to wild-type littermates. This may represent the lack of sensitivity of the systems in place to detect the relatively small changes in food intake and energy expenditure. If so this demonstrates the fine balance in energy homeostasis, where small changes could tip the scale leading to significant weight gain. However, in light of the differences between $\mathrm{Mc}_{4} \mathrm{r}^{-/-}$and Mrap2 ${ }^{-/-}$mice, it is likely that MC4R independent mechanisms as well as MCR independent pathways are at play. The complexity of these proteins and how they regulate MCR and GPCR function is only just beginning to be explored.

\section{Acknowledgments}

Research on MRAPs is supported by an MRC/Academy of Medical Sciences Clinician Scientist Fellowship to LFC (grant number G0802796).

Chai, B. X., Neubig, R. R., Millhauser, G. L., Thompson, D. A., Jackson, P. J., Barsh G. S., et al. (2003). Inverse agonist activity of agouti and agouti-related protein. Peptides 24, 603-609. doi: 10.1016/S0196-9781(03)00104-9

Chambers, J. C., Elliott, P., Zabaneh, D., Zhang, W., Li, Y., Froguel, P., et al. (2008). Common genetic variation near MC4R is associated with waist circumference and insulin resistance. Nat. Genet. 40, 716-718. doi: 10.1038/ng.156

Chan, L. F., Webb, T. R., Chung, T. T., Meimaridou, E., Cooray, S. N., Guasti, L., et al. (2009). MRAP and MRAP2 are bidirectional regulators of the melanocortin receptor family. Proc. Natl. Acad. Sci. U.S.A. 106, 6146-6151. doi: 10.1073/pnas.0809918106

Chen, A. S., Marsh, D. J., Trumbauer, M. E., Frazier, E. G., Guan, X. M., Yu, H., et al. (2000). Inactivation of the mouse melanocortin-3 receptor results in increased fat mass and reduced lean body mass. Nat. Genet. 26, 97-102. doi: $10.1038 / 79254$

Chen, W., Kelly, M. A., Opitz-Araya, X., Thomas, R. E., Low, M. J., and Cone, R. D. (1997). Exocrine gland dysfunction in MC5-R-deficient mice: evidence for coordinated regulation of exocrine gland function by melanocortin peptides. Cell 91, 789-798. doi: 10.1016/S0092-8674(00)80467-5

Chida, D., Nakagawa, S., Nagai, S., Sagara, H., Katsumata, H., Imaki, T., et al. (2007). Melanocortin 2 receptor is required for adrenal gland development, steroidogenesis, and neonatal gluconeogenesis. Proc. Natl. Acad. Sci. U.S.A. 104, 18205-18210. doi: 10.1073/pnas.0706953104

Chung, T. T., Chan, L. F., Metherell, L. A., and Clark, A. J. (2010). Phenotypic characteristics of familial glucocorticoid deficiency (FGD) type 1 and 2. Clin. Endocrinol. (Oxf.) 72, 589-594. doi: 10.1111/j.1365-2265.2009.03663.x

Clark, A. J., and Weber, A. (1998). Adrenocorticotropin insensitivity syndromes. Endocr. Rev. 19, 828-843. doi: 10.1210/edrv.19.6.0351

Clark, A. J., McLoughlin, L., and Grossman, A. (1993). Familial glucocorticoid deficiency associated with point mutation in the adrenocorticotropin receptor. Lancet 341, 461-462. doi: 10.1016/0140-6736(93)90208-X

Cone, R. D. (2006). Studies on the physiological functions of the melanocortin system. Endocr. Rev. 27, 736-749. doi: 10.1210/er.2006-0034

Cooray, S. N., Almiro Do Vale, I., Leung, K. Y., Webb, T. R., Chapple, J. P., Egertova, M., et al. (2008). The melanocortin 2 receptor accessory protein exists as a homodimer and is essential for the function of the melanocortin 2 receptor in the mouse y1 cell line. Endocrinology 149, 1935-1941. doi: 10.1210/en.2007-1463

Dores, R. M. (2013). Observations on the evolution of the melanocortin receptor gene family: distinctive features of the melanocortin-2 receptor. Front Neurosci. 7:28. doi: 10.3389/fnins.2013.00028

Elias, L. L., Huebner, A., Metherell, L. A., Canas, A., Warne, G. L., Bitti, M. L., et al. (2000). Tall stature in familial glucocorticoid deficiency. Clin. Endocrinol. (Oxf.) 53, 423-430. doi: 10.1046/j.1365-2265.2000.01122.x 
Farooqi, I. S., Keogh, J. M., Yeo, G. S., Lank, E. J., Cheetham, T., and O'Rahilly, S. (2003). Clinical spectrum of obesity and mutations in the melanocortin 4 receptor gene. N.Engl. J. Med. 348, 1085-1095. doi: 10.1056/nejmoa022050

Gardiner, K., Slavov, D., Bechtel, L., and Davisson, M. (2002). Annotation of human chromosome 21 for relevance to Down syndrome: gene structure and expression analysis. Genomics 79, 833-843. doi: 10.1006/geno.2002.6782

Getting, S. J., Lam, C. W., Leoni, G., Gavins, F. N., Grieco, P., and Perretti, M. (2006). [D-Trp8]-gamma-melanocyte-stimulating hormone exhibits antiinflammatory efficacy in mice bearing a nonfunctional MC1R (recessive yellow e/e mouse). Mol. Pharmacol. 70, 1850-1855. doi: 10.1124/mol.106.028878

Gorrigan, R. J., Guasti, L., King, P., Clark, A. J., and Chan, L. F. (2011). Localisation of the melanocortin-2-receptor and its accessory proteins in the developing and adult adrenal gland. J. Mol. Endocrinol. 46, 227-232. doi: 10.1530/JME-11-0011

Griffon, N., Mignon, V., Facchinetti, P., Diaz, J., Schwartz, J. C., and Sokoloff, P. (1994). Molecular cloning and characterization of the rat fifth melanocortin receptor. Biochem. Biophys. Res. Commun. 200, 1007-1014. doi: 10.1006/bbrc. 1994.1550

He, L., Gunn, T. M., Bouley, D. M., Lu, X. Y., Watson, S. J., Schlossman, S. F., et al. (2001). A biochemical function for attractin in agouti-induced pigmentation and obesity. Nat. Genet. 27, 40-47. doi: 10.1038/89022

Hinkle, P. M., and Sebag, J. A. (2009). Structure and function of the melanocortin2 receptor accessory protein (MRAP). Mol. Cell Endocrinol. 300, 25-31. doi: 10.1016/j.mce.2008.10.041

Hofland, J., Delhanty, P. J., Steenbergen, J., Hofland, L. J., van Koetsveld, P. M., van Nederveen, F. H., et al. (2012). Melanocortin 2 receptor-associated protein (MRAP) and MRAP2 in human adrenocortical tissues: regulation of expression and association with ACTH responsiveness. J. Clin. Endocrinol. Metab. 97, E747-E754. doi: 10.1210/jc.2011-2328

Hu, S., Yao, G., Wang, Y., Xu, H., Ji, X., He, Y., et al. (2014). Transcriptomic changes during the pre-receptive to receptive transition in human endometrium detected by RNA-Seq. J. Clin. Endocrinol. Metab. 99, E2744-E2753. doi: 10.1210/jc.2014-2155

Hughes, C. R., Chung, T. T., Habeb, A. M., Kelestimur, F., Clark, A. J., and Metherell, L. A. (2010). Missense mutations in the melanocortin 2 receptor accessory protein that lead to late onset familial glucocorticoid deficiency type 2. J. Clin. Endocrinol. Metab. 95, 3497-3501. doi: 10.1210/jc.2009-2731

Huszar, D., Lynch, C. A., Fairchild-Huntress, V., Dunmore, J. H., Fang, Q., Berkemeier, L. R., et al. (1997). Targeted disruption of the melanocortin-4 receptor results in obesity in mice. Cell 88, 131-141. doi: 10.1016/S00928674(00)81865-6

Kay, E. I., Botha, R., Montgomery, J. M., and Mountjoy, K. G. (2013a). hMRAPa specifically alters hMC4R molecular mass and N-linked complex glycosylation in HEK293 cells. J. Mol. Endocrinol. 50, 217-227. doi: 10.1530/JME-12-0220

Kay, E. I., Botha, R., Montgomery, J. M., and Mountjoy, K. G. (2013b). hMRAPa increases alphaMSH-induced hMC1R and hMC3R functional coupling and hMC4R constitutive activity. J. Mol. Endocrinol. 50, 203-215. doi: 10.1530/JME-12-0221

Kiefer, L. L., Ittoop, O. R., Bunce, K., Truesdale, A. T., Willard, D. H., Nichols, J. S., et al. (1997). Mutations in the carboxyl terminus of the agouti protein decrease agouti inhibition of ligand binding to the melanocortin receptors. Biochemistry 36, 2084-2090. doi: 10.1021/bi962647v

Kim, N. S., Kim, Y. J., Cho, S. Y., Lee, T. R., and Kim, S. H. (2013). Transcriptional activation of melanocortin 2 receptor accessory protein by PPARgamma in adipocytes. Biochem. Biophys. Res. Commun. 439, 401-406. doi: 10.1016/j.bbrc.2013.08.061

Lee, Y. S., Poh, L. K., Kek, B. L., and Loke, K. Y. (2007). The role of melanocortin 3 receptor gene in childhood obesity. Diabetes 56, 2622-2630. doi: 10.2337/db070225

Leoni, G., Patel, H. B., Sampaio, A. L., Gavins, F. N., Murray, J. F., Grieco, P., et al. (2008). Inflamed phenotype of the mesenteric microcirculation of melanocortin type 3 receptor-null mice after ischemia-reperfusion. FASEB J. 22, 4228-4238. doi: $10.1096 /$ fj.08-113886

Lim, B. K., Huang, K. W., Grueter, B. A., Rothwell, P. E., and Malenka, R. C. (2012). Anhedonia requires MC4R-mediated synaptic adaptations in nucleus accumbens. Nature 487, 183-189. doi: 10.1038/nature11160

Liu, H., Kishi, T., Roseberry, A. G., Cai, X., Lee, C. E., Montez, J. M., et al. (2003). Transgenic mice expressing green fluorescent protein under the control of the melanocortin-4 receptor promoter. J. Neurosci. 23, 7143-7154.
Loos, R. J., Lindgren, C. M., Li, S., Wheeler, E., Zhao, J. H., Prokopenko, I., et al. (2008). Common variants near MC4R are associated with fat mass, weight and risk of obesity. Nat. Genet. 40, 768-775. doi: 10.1038/ng.140

Lu, D., Willard, D., Patel, I. R., Kadwell, S., Overton, L., Kost, T., et al. (1994). Agouti protein is an antagonist of the melanocyte-stimulating-hormone receptor. Nature 371, 799-802. doi: 10.1038/371799a0

MacNeil, D. J., Howard, A. D., Guan, X., Fong, T. M., Nargund, R. P., Bednarek, M. A., et al. (2002). The role of melanocortins in body weight regulation: opportunities for the treatment of obesity. Eur. J. Pharmacol. 450, 93-109. doi: 10.1016/S0014-2999(02)01989-1

Mencarelli, M., Dubern, B., Alili, R., Maestrini, S., Benajiba, L., Tagliaferri, M., et al. (2011). Rare melanocortin-3 receptor mutations with in vitro functional consequences are associated with human obesity. Hum. Mol. Genet. 20, 392-399. doi: $10.1093 / \mathrm{hmg} / \mathrm{ddq} 472$

Metherell, L. A., Chapple, J. P., Cooray, S., David, A., Becker, C., Ruschendorf, F., et al. (2005). Mutations in MRAP, encoding a new interacting partner of the ACTH receptor, cause familial glucocorticoid deficiency type 2. Nat. Genet. 37, 166-170. doi: 10.1038/ng1501

Mo, X. L., and Tao, Y. X. (2013). Activation of MAPK by inverse agonists in six naturally occurring constitutively active mutant human melanocortin-4 receptors. Biochim. Biophys. Acta 1832, 1939-1948. doi: 10.1016/j.bbadis.2013.06.006

Moller, C. L., Raun, K., Jacobsen, M. L., Pedersen, T. A., Holst, B., Conde-Frieboes, K. W., et al. (2011). Characterization of murine melanocortin receptors mediating adipocyte lipolysis and examination of signalling pathways involved. Mol. Cell Endocrinol. 341, 9-17. doi: 10.1016/j.mce.2011.03.010

Montero-Melendez, T., Madeira, M. F., Norling, L. V., Alsam, A., Curtis, M. A., da Silva, T. A., et al. (2014). Association between periodontal disease and inflammatory arthritis reveals modulatory functions by melanocortin receptor type 3. Am. J. Pathol. 184, 2333-2341. doi: 10.1016/j.ajpath.2014.04.009

Nijenhuis, W. A., Oosterom, J., and Adan, R. A. (2001). AgRP(83-132) acts as an inverse agonist on the human-melanocortin-4 receptor. Mol. Endocrinol. 15, 164-171. doi: 10.1210/mend.15.1.0578

Noon, L. A., Franklin, J. M., King, P. J., Goulding, N. J., Hunyady, L., and Clark, A. J. (2002). Failed export of the adrenocorticotrophin receptor from the endoplasmic reticulum in non-adrenal cells: evidence in support of a requirement for a specific adrenal accessory factor. J. Endocrinol. 174, 17-25. doi: $10.1677 /$ joe. 0.1740017

O'Shaughnessy, P. J., Baker, P. J., Monteiro, A., Cassie, S., Bhattacharya, S., and Fowler, P. A. (2007). Developmental changes in human fetal testicular cell numbers and messenger ribonucleic acid levels during the second trimester. J. Clin. Endocrinol. Metab. 92, 4792-4801. doi: 10.1210/jc.2007-1690

Ollmann, M. M., Wilson, B. D., Yang, Y. K., Kerns, J. A., Chen, Y., Gantz, I., et al. (1997). Antagonism of central melanocortin receptors in vitro and in vivo by agouti-related protein. Science 278, 135-138. doi: 10.1126/science.278. 5335.135

Panaro, B. L., Tough, I. R., Engelstoft, M. S., Matthews, R. T., Digby, G. J., Moller, C. L., et al. (2014). The Melanocortin- 4 receptor is expressed in enteroendocrine $\mathrm{L}$ cells and regulates the release of peptide YY and Glucagon-like peptide 1 in vivo. Cell Metab. 20, 1018-1029. doi: 10.1016/j.cmet.2014.10.004

Park, J., Sharma, N., and Cutting, G. R. (2014). Melanocortin 3 receptor has a 5 ' exon that directs translation of apically localized protein from the second in-frame ATG. Mol. Endocrinol. 28, 1547-1557. doi: 10.1210/me. 2014-1105

Pritchard, L. E., Turnbull, A. V., and White, A. (2002). Pro-opiomelanocortin processing in the hypothalamus: impact on melanocortin signalling and obesity. J. Endocrinol. 172, 411-421. doi: 10.1677/joe.0.1720411

Rodrigues, A. R., Almeida, H., and Gouveia, A. M. (2013). Alpha-MSH signalling via melanocortin 5 receptor promotes lipolysis and impairs reesterification in adipocytes. Biochim. Biophys. Acta 1831, 1267-1275. doi: 10.1016/j.bbalip.2013.04.008

Roy, S., Perron, B., and Gallo-Payet, N. (2010). Role of asparagine-linked glycosylation in cell surface expression and function of the human adrenocorticotropin receptor (melanocortin 2 receptor) in 293/FRT cells. Endocrinology 151, 660-670. doi: 10.1210/en.2009-0826

Roy, S., Rached, M., and Gallo-Payet, N. (2007). Differential regulation of the human adrenocorticotropin receptor [melanocortin-2 receptor (MC2R)] by human MC2R accessory protein isoforms alpha and beta in isogenic 
human embryonic kidney 293 cells. Mol. Endocrinol. 21, 1656-1669. doi: 10.1210/me.2007-0041

Rumie, H., Metherell, L. A., Clark, A. J., Beauloye, V., and Maes, M. (2007). Clinical and biological phenotype of a patient with familial glucocorticoid deficiency type 2 caused by a mutation of melanocortin 2 receptor accessory protein. Eur. J. Endocrinol. 157, 539-542. doi: 10.1530/EJE-07-0242

Sebag, J. A., and Hinkle, P. M. (2007). Melanocortin-2 receptor accessory protein MRAP forms antiparallel homodimers. Proc. Natl. Acad. Sci. U.S.A. 104, 20244-20249. doi: 10.1073/pnas.0708916105

Sebag, J. A., and Hinkle, P. M. (2009). Opposite effects of the melanocortin2 (MC2) receptor accessory protein MRAP on MC2 and MC5 receptor dimerization and trafficking. J. Biol. Chem. 284, 22641-22648. doi: 10.1074/jbc.m109.022400

Sebag, J. A., and Hinkle, P. M. (2010). Regulation of G protein-coupled receptor signaling: specific dominant-negative effects of melanocortin 2 receptor accessory protein 2. Sci. Signal. 3:ra28. doi: 10.1126/scisignal. 2000593

Sebag, J. A., Zhang, C., Hinkle, P. M., Bradshaw, A. M., and Cone, R. D. (2013). Developmental control of the melanocortin-4 receptor by MRAP2 proteins in zebrafish. Science 341, 278-281. doi: 10.1126/science.1232995

Shutter, J. R., Graham, M., Kinsey, A. C., Scully, S., Luthy, R., and Stark, K. L. (1997). Hypothalamic expression of ART, a novel gene related to agouti, is up-regulated in obese and diabetic mutant mice. Genes Dev. 11, 593-602. doi: 10.1101/gad.11.5.593

Smith, S. R., Gawronska-Kozak, B., Janderova, L., Nguyen, T., Murrell, A., Stephens, J. M., et al. (2003). Agouti expression in human adipose tissue: functional consequences and increased expression in type 2 diabetes. Diabetes 52, 2914-2922. doi: 10.2337/diabetes.52.12.2914

Sohn, J. W., Harris, L. E., Berglund, E. D., Liu, T., Vong, L., Lowell, B. B., et al. (2013). Melanocortin 4 receptors reciprocally regulate sympathetic and parasympathetic preganglionic neurons. Cell 152, 612-619. doi: 10.1016/j.cell.2012.12.022

Star, R. A., Rajora, N., Huang, J., Stock, R. C., Catania, A., and Lipton, J. M. (1995). Evidence of autocrine modulation of macrophage nitric oxide synthase by alpha-melanocyte-stimulating hormone. Proc. Natl. Acad. Sci. U.S.A. 92, 8016-8020. doi: 10.1073/pnas.92.17.8016

Sutton, G. M., Begriche, K., Kumar, K. G., Gimble, J. M., Perez-Tilve, D., Nogueiras, R., et al. (2010). Central nervous system melanocortin-3 receptors are required for synchronizing metabolism during entrainment to restricted feeding during the light cycle. FASEB J. 24, 862-872. doi: 10.1096/fj.09142000

Sutton, G. M., Perez-Tilve, D., Nogueiras, R., Fang, J., Kim, J. K., Cone, R. D., et al. (2008). The melanocortin-3 receptor is required for entrainment to meal intake. J. Neurosci. 28, 12946-12955. doi: 10.1523/JNEUROSCI.361508.2008

Sutton, G. M., Trevaskis, J. L., Hulver, M. W., McMillan, R. P., Markward, N. J., Babin, M. J., et al. (2006). Diet-genotype interactions in the development of the obese, insulin-resistant phenotype of C57BL/6J mice lacking melanocortin-3 or -4 receptors. Endocrinology 147, 2183-2196. doi: 10.1210/en. 2005-1209
Swope, V. B., Jameson, J. A., McFarland, K. L., Supp, D. M., Miller, W. E., McGraw, D. W., et al. (2012). Defining MC1R regulation in human melanocytes by its agonist alpha-melanocortin and antagonists agouti signaling protein and beta-defensin 3. J. Invest. Dermatol. 132, 2255-2262. doi: 10.1038/jid.2012.135

Tontonoz, P., Hu, E., and Spiegelman, B. M. (1994). Stimulation of adipogenesis in fibroblasts by PPAR gamma 2, a lipid-activated transcription factor. Cell 79, 1147-1156. doi: 10.1016/0092-8674(94)90006-X

Vage, D. I., Lu, D., Klungland, H., Lien, S., Adalsteinsson, S., and Cone, R. D. (1997). A non-epistatic interaction of agouti and extension in the fox, Vulpes vulpes. Nat. Genet. 15, 311-315. doi: 10.1038/ng0397-311

Vaisse, C., Clement, K., Guy-Grand, B., and Froguel, P. (1998). A frameshift mutation in human MC4R is associated with a dominant form of obesity. Nat. Genet. 20, 113-114. doi: 10.1038/2407

van der Kraan, M., Adan, R. A., Entwistle, M. L., Gispen, W. H., Burbach, J. P., and Tatro, J. B. (1998). Expression of melanocortin-5 receptor in secretory epithelia supports a functional role in exocrine and endocrine glands. Endocrinology 139, 2348-2355. doi: 10.1210/en.139.5.2348

van der Ploeg, L. H., Martin, W. J., Howard, A. D., Nargund, R. P., Austin, C. P., Guan, X., et al. (2002). A role for the melanocortin 4 receptor in sexual function. Proc. Natl. Acad. Sci. U.S.A. 99, 11381-11386. doi: 10.1073/pnas.172378699

Vinson, G. P., Whitehouse, B. J., Dell, A., Etienne, T., and Morris, H. R. (1980). Characterisation of an adrenal zona glomerulosa-stimulating component of posterior pituitary extracts as alpha-MSH. Nature 284, 464-467. doi: $10.1038 / 284464 \mathrm{a} 0$

Webb, T. R., and Clark, A. J. (2010). Minireview: the melanocortin 2 receptor accessory proteins. Mol. Endocrinol. 24, 475-484. doi: 10.1210/me.2009-0283

Xu, A., Choi, K. L., Wang, Y., Permana, P. A., Xu, L. Y., Bogardus, C., et al. (2002). Identification of novel putative membrane proteins selectively expressed during adipose conversion of 3T3-L1 cells. Biochem. Biophys. Res. Commun. 293, 1161-1167. doi: 10.1016/S0006-291X(02)00354-6

Yang, Y. (2011). Structure, function and regulation of the melanocortin receptors. Eur. J. Pharmacol. 660, 125-130. doi: 10.1016/j.ejphar.2010.12.020

Yeo, G. S., Farooqi, I. S., Aminian, S., Halsall, D. J., Stanhope, R. G., and O’Rahilly, S. (1998). A frameshift mutation in MC4R associated with dominantly inherited human obesity. Nat. Genet. 20, 111-112.

Zhong, Q., Sridhar, S., Ruan, L., Ding, K. H., Xie, D., Insogna, K., et al. (2005). Multiple melanocortin receptors are expressed in bone cells. Bone 36, 820-831. doi: 10.1016/j.bone.2005.01.020

Conflict of Interest Statement: The authors declare that the research was conducted in the absence of any commercial or financial relationships that could be construed as a potential conflict of interest.

Copyright (c) 2015 Jackson, Ramachandrappa, Clark and Chan. This is an openaccess article distributed under the terms of the Creative Commons Attribution License (CC BY). The use, distribution or reproduction in other forums is permitted, provided the original author(s) or licensor are credited and that the original publication in this journal is cited, in accordance with accepted academic practice. No use, distribution or reproduction is permitted which does not comply with these terms. 